ModaPalavra E-periódico

\title{
A camiseta como suporte político
}

The t-shirt as political stand

Salma Soria

Pós-graduando Roteiro para Cinema e Tv na Universidade Veiga de Almeida - RJ salmasoria@gmail.com 


\section{A camiseta como suporte político}

The t-shirt as political stand

Salma Soria

\section{Resumo}

As camisetas estampadas com frases filantrópicas ou campanhas de mobilização social, sejam elas produzidas por empresas de alto luxo ou por governos, vinculam o cidadão numa série de situações onde o jogo da aparência é muito mais complexo do que parece. $\mathrm{O}$ artigo objetiva analisar frases das camisetas estampadas de empresas americanas de luxo (burguesia) que possuem influência mundial $\mathrm{e}$ camisetas distribuídas pelos governos municipal e estadual do Rio de Janeiro (população carente). Como aporte teórico nas relações burguesas está Roland Barthes em Mitologias; sobre as relações de consumo e política a obra Consumidores $e$ Cidadãos de Néstor García Canclini.

Palavras- chave: camiseta, moda e política, filantropia

\begin{abstract}
The printed shirts with philanthropic phrases or social mobilization campaigns, made by high luxury companies or governments, links the citizen in a number of situations where the appearance is much more complex than it seems. The article aims to analyze the philanthropic t-shirts of the american luxury companies which have global influence and t-shirts with prints produced by municipal and state governments of Rio de Janeiro.
\end{abstract}

Keywords: $t$-shirt, fashion and politics, philanthropy 


\title{
1. Introdução
}

\author{
"Quando uma peça muda realmente? Ou seja, quando há realmente \\ história? "-Roland Barthes ${ }^{1}$
}

Roupa não é exclusividade da moda. Ter acesso ao vestuário não é elemento de luxo. Ela é assegurada pela Declaração Universal dos direitos humanos ${ }^{2}$ :"Todo ser humano tem direito a um padrão de vida capaz de assegurar a si e a sua família saúde e bem-estar, inclusive alimentação, vestuário...”. E também pela Constituição Brasileira de 1988, em que vinculam o pagamento de salário mínimo capaz de atender as necessidades vitais básicas, tais como a compra de vestuário ${ }^{3}$.

Roupa: direito universal, constitucional, comportamental, civil. A questão é, dentro do ato político o que fazem da roupa? Não falaremos das normas do vestuário de parlamentares ou dos padrões de vestimentas impostas por leis de algumas sociedades, mas, das práticas utilizadas pelos órgãos governamentais e privados através das camisetas estampadas com mensagens de intenção de voto, prevenção ou ação humanitária. Estariam elas nos protegendo/alertando com suas mensagens? Por que a escolha da camiseta? Um indício da preferência desse elemento do vestuário como suporte na política, vem de um texto do filósofo Luiz Carlos Maciel, no livro A História da Camiseta:

\footnotetext{
"O caráter anticonvencional do lançamento da camiseta como roupa de todos os dias, nos anos 50, assinala a vocação libertária que haveria de leva-la à política. A camiseta parece ter-se emancipado da sua condição subalterna anterior para dar voz à necessidade de protesto das pessoas. A contestação parecia seu destino, desde o início" (MACIEL, 1988, p. 62).
}

A informalidade da camiseta permite a circulação em inúmeros locais, na mesma maneira em que a estampa emite importantes informações sobre momentos políticos, como foi o caso da campanha Diretas Já:

“A palavra-de-ordem das Diretas Já sofreu, num primeiro momento, um boicote por parte dos veículos de comunicação tradicionais. Foi preciso o

\footnotetext{
${ }^{1}$ Roland Barthes no artigo "História e sociologia do vestuário", p. 260 na obra Inéditos Vol. 3. Imagem e Moda, Editora Martins Fontes, 2005.

${ }^{2}$ Artigo 25, parágrafo $1^{\circ}$

${ }^{3}$ Artigo $7^{\circ}$, inciso IV
} 
movimento espalhar-se pela população e tornar-se uma quase unanimidade nacional para que os meios eletrônicos aderissem. Ao contrário dos grandes jornais e das tevês, as camisetas são veículos de divulgação cujo controle é acessível ao grande público. Na medida em que o movimento se utiliza de recursos como esse, consegue ultrapassar o bloqueio e sair da clandestinidade, multiplica-se, ganha repercussão e acesso aos meios eletrônicos (...) A camiseta serviu de cimento social, de multiplicador, e arrastou os outros meios de comunicação atrás dela" (MACIEL, 1988. p.69).

\section{Mobilização filantrópica do mercado de luxo}

Em contrapartida, a moda de alto luxo também utiliza o mesmo suporte para vincular ações com funções muito próximas que os meios políticos promovem, porém, ganham outro nome: ação filantrópica, numa desvinculação da política. Por serem empresas privadas, não possuem o dever com programas assistencialistas, já que o maior objetivo é o lucro e a expansão de seus negócios de luxo. Em Mitologias, Roland Barthes explica na burguesia, a política como um fragmento de ideologia.

\footnotetext{
"Na sociedade burguesa não há cultura, moral nem arte proletárias: ideologicamente, tudo o que não é burguês é obrigado a pedir emprestado à burguesia. A ideologia burguesa pode, portanto, preencher tudo e, sem qualquer risco, perder o seu nome: ninguém lhe irá devolver; ela pode, sem encontrar resistência, apresentar o teatro, a arte e o homem burguês sob seus análogos eternos”. (BARTHES, 2013, p. 231).
}

A sociedade não burguesa pede direta ou indiretamente para as grifes de alto luxo, ações sociais que apliquem aos menos favorecidos, e eles promovem ações filantrópicas que teóricamente não são criadas com o objetivo de ser moda. Muito embora, sendo divulgadas por poderosas grifes, usadas por popstars, top models e grandes influenciadores digitais, camisetas humanitárias podem virar acessórios imediatos, mudando o percurso de seu significado.

Ralph Lauren em O Câncer de Mama no Alvo da Moda, é um interessante caso em que o consumo ajudou a saúde pública e ao mesmo tempo, uma referência de modismo imediato. O slogan é até hoje aceito dentro e fora do campo da moda, pois Ralph Lauren é personalidade criadora e disseminadora de tendências. Ele cria coleções 
inspiradas na alta aristocracia americana. $\mathrm{O}$ alvo criado por ele se popularizou no Brasil. Foram 418 mil camisetas vendidas no primeiro ano:

Quando desembarcou no País, em 1995, a campanha O Câncer de Mama no Alvo da Moda também foi logo acolhida pelo mundo da moda e das celebridades. Não faltou apoio. Ao contrário, O Câncer de Mama no Alvo da Moda ganhou passarelas, ruas, espaços na mídia, eventos esportivos, etc. Circulou entre produtos dos mais variados segmentos e públicos. Para se ter uma ideia de como começou bem a causa nobre no Brasil, já na primeira edição a Campanha vendeu 418 mil camisetas e entrou para o livro dos recordes (Guiness Book Edição 1995). Isto porque a camiseta mais cara do mundo, com o autógrafo da apresentadora Xuxa, foi leiloada por R\$ 81 mil. Este foi o primeiro dos recordes que seriam batidos em sua história ${ }^{4}$.

O símbolo da campanha O Câncer de Mama no Alvo da Moda é sóbrio e elegante (dois tons de azuis e um de branco) não estando diretamente vinculada nas campanhas publicitárias da Ralph Lauren. A campanha foi repaginada nos Estados Unidos e surgiu anos atrás como Pink Pony.

Renomados estilistas não vinculam diretamente suas logomarcas em tragédias sociais. Embora a motivação das campanhas seja descrita como humanitárias, inspiramse em imagens agradáveis ainda que isso signifique o escapismo da realidade (Do alvo azul e branco passando para o pônei rosa). Por quê a negativa? Essa relação de escape é descrita ainda em Mitologias como "A burguesia absorve ininterruptamente na sua ideologia toda uma humanidade que não possui um estatuto profundo e que só pode vivê-lo no imaginário, isto é, numa fixação e num empobrecimento da consciência" (BARTHES, 2013, p.233).

\footnotetext{
${ }^{4}$ Trecho retirado do site oficial do Câncer de Mama no Alvo da Moda, seção "Nossa História”.
} 
Figura 1: Pink Pony

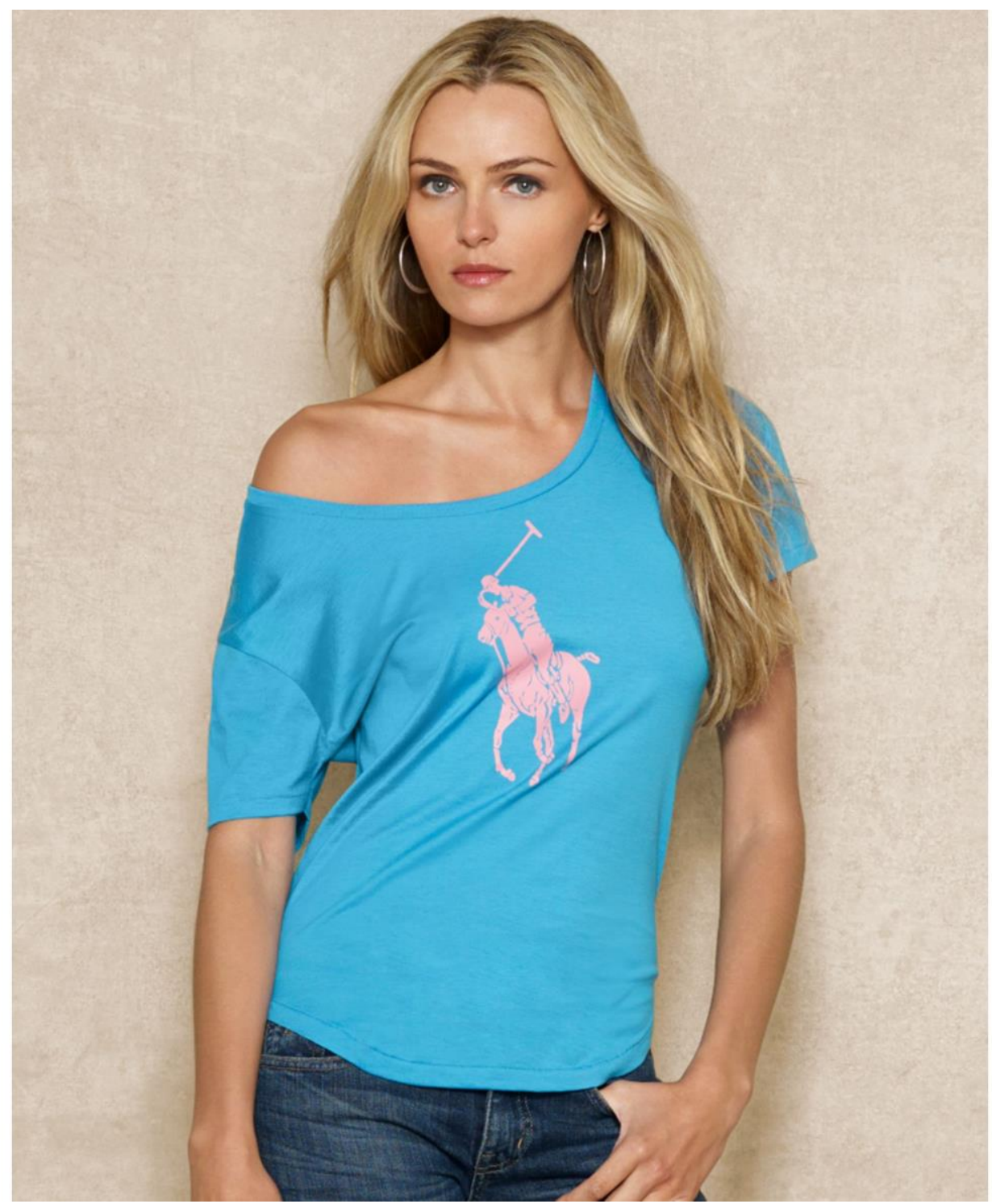

Fonte: lyst.com

A modelo Valentina Zelyaeva (figura 1) fotografada em charmosa pose, usa uma camiseta com recorte de gola que evidencia o colo. A logo da camiseta esvazia sua representação. O pink pony possui como diferença a cor rosa da logo, centralização do ícone e seu aumento que ocupa parte da peça. Não há no produto, nenhuma inscrição que possa indicar para outras pessoas que em tese, possam não conhecer a causa, que a camiseta se trata de uma campanha contra o câncer. Continua afirmada, como uma camiseta Ralph Lauren antes de qualquer coisa. O lucro resultante das vendas é doado para várias iniciativas de caridade ao redor do mundo, incluindo o Ralph Lauren Center, 
em Nova Iorque, local de prevenção e tratamento contra o câncer ${ }^{5}$.

Mais um curioso caso são as camisetas, regatas e moletons da série filantrópica do designer Alexander Wang. O tema da causa: "Do Something", ou, faça alguma coisa. A campanha publicitária em torno da camiseta contou com a adesão de 38 artistas incluindo: Kate Moss, Rod Stewart, Kim Kardashian, Cara Delevigne. As camisetas, em formato unissex, custam 45 dólares e 50\% do valor vai para a causa dosomething.org, comunidade virtual que possui mais de 5 milhões de membros espalhados pelo mundo que tem como lema "qualquer causa, qualquer hora, em qualquer lugar".

\footnotetext{
${ }^{5}$ Fonte: http://global.ralphlauren.com/en-us/About/Philanthropy/Pages/pink_pony

${ }^{6}$ Fonte: dosomenthing.org
} 
Figura 2: Top Lara Stone para a campanha



Fonte: harpersbazaar.co.uk

Outro designer americano que promove ações de filantropia: Michael Kors e seu Watch Hunger Stop, livre tradução cronômetro da fome, ação em parceria com as Nações Unidas. Desta vez, o consumidor não precisa comprar a camiseta. Ela é dada, gratuitamente. O principal ato do programa consiste em reverter o lucro das vendas do relógio da linha Watch Hunger Stop. Para cada relógio vendido, cem crianças terão acesso a uma refeição nutritiva em lugares de extrema pobreza ${ }^{7}$.

\footnotetext{
${ }^{7}$ Fonte: http://destinationkors.michaelkors.com/kors-cares/watch-hunger-stop/introducing-bradshaw-100/
} 
Figura 3: Ação Michael Kors

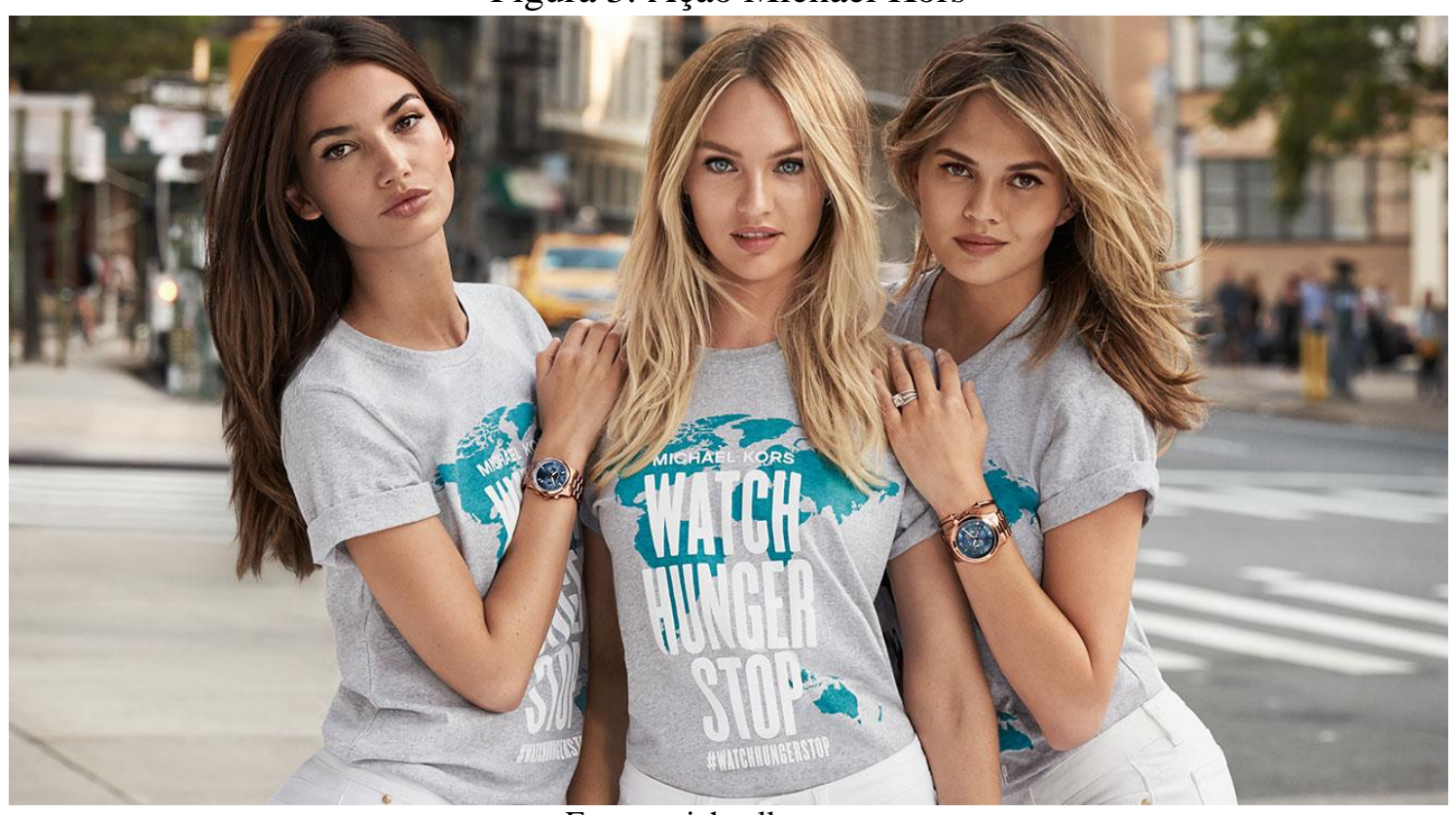

Fonte: michaelkors.com

Não é excitante que grandes empresas distribuam um pouco de seus lucros em causas sociais importantes? Não é curioso que para tal efeito eles precisem que novamente o consumidor compre? Estamos num processo em que os conflitos públicos e sociais se alinham com os atores das grandes indústrias, gerando todo o tipo de adaptação/alienação no jogo civil como um simulacro eletrônico. Nestór Garcia Canclini, em Consumidores e Cidadãos, fala da substituição da verdade pelo videogame:

\footnotetext{
"Neste videogame em que os signos são substituídos pelo simulacro, desaparece qualquer "pergunta sobre a verdade (seja esta definida como efeito de discurso ou de outro modo); todas as perguntas se relacionam com a eficácia, a destreza, a velocidade e a distância. Quando se perde a distinção entre o real e o simbólico, quando a pergunta sobre a legitimidade das representações se extravia e tudo é simulacro, não sobra lugar para a confrontação racional de posições, nem para a troca, nem, é óbvio, para a negociação. Não há uma pergunta sobre a identidade porque não existe um discurso relacionado a algo que se postule como realidade efetiva: apenas a sucessão desordenada de imagens do videogame, sem referências externas à pseudonarrativa visual" (CANCLINI, 2006, p. 210)
}

Há um dilema na moda: como falar de conflitos étnicos, éticos, políticos, sociais, sem perder o próprio bom gosto -que parece ser a maior ética dentro do universo da 
moda?

No momento em que tudo é consumo, influência digital, as camisetas com mensagens que simbolizam a ajuda humanitária, produzem uma presentificação da cidadania, ainda que grifadas. Canclini afirma:

\footnotetext{
"Com efeito costuma-se imaginar o consumo como o lugar do suntuoso e do supérfluo, no qual os impulsos primários dos indivíduos poderiam alinhar-se com estudos de mercado e táticas publicitárias. Além disso, reduz-se a cidadania a uma questão política, e se acredita que as pessoas votam e atuam em relação ás questões públicas somente em razão de suas conviç̧ões individuais e pela maneira como raciocinam nos confrontos de ideias" (CANCLINI, 2006, p.35).
}

Quem compra uma camiseta que promete erradicar a fome na África ou que promete ações que previnam o câncer de mama, dá um voto comercial-civil naquelas empresas para que elas pudessem agir. Os consumidores que acreditam que vestindo as camisetas deram um enorme passo, podem ali também estarem presos neste único passo, já que aquela camiseta estampada, cheirosa, etiquetada, no cabide, era tudo o que podiam fazer para erradicar a fome na África? Até outra empresa lançar outra camiseta de apelo aproximado, posada por artistas? Estaremos condicionados a vestirmos camisetas em que nos dizem tudo, produzindo mais uma imagem midiática? A negociação social será através de camisetas? "Nesta etapa pós política, em que se age como se não houvesse luta, tem-se a impressão de que não é necessário negociar; apenas se fotografam, se filmam, se televisionam e se consomem essas imagens" (CANCLINI, 2006, p.209)

Não seria revolucionário o coletivo da moda mover ações de cidadania em torno de suas práticas? Começando pelas éticas em produção, terceirização, meio-ambiente, consumo e impostos? Não é óbvio privilegiar as novidades da moda para quem já tem o closet abarrotado?

Para Barthes há uma lógica “...a cozinha com que sonhamos, o vestuário que usamos, tudo, na nossa vida cotidiana, é tributário da representação que a burguesia criou para ela e para nós nas relações entre o homem e o mundo" (2013, p. 232). 


\section{A aparência}

O homem criou o vestir-se para o sucesso: há normas de conduta onde por exemplo, se esse homem bem-sucedido vestisse a mesma camiseta do agente comunitário (fig. 4), como ele estaria alinhado dentro da narrativa fashion?

Figura 4: Camiseta Alerta Rio



Fonte: arquivo da autora

Os agentes comunitários em áreas de risco da cidade do Rio de Janeiro são identificados pela camiseta "Ao ouvir a sirene". A estampa descreve sobre o que cada morador deve fazer: "Mantenha a calma/ Pegue seus documentos e remédios necessários/ Desligue a chave geral da luz e feche o gás/ Dirija-se para local seguro ou 
Ponto de Apoio/ Aguarde orientação para retorno à sua casa".

Esta camiseta, ao lado da tecnologia, faz parte do material de prevenção e objetiva esclarecer a população sobre como proceder em caso de emergência. A Defesa Civil, mediante o relatório da Prefeitura decide emitir ou não o aviso sonoro. Além disso, são enviados mensagens de texto via celular para líderes e agentes comunitários treinados. O sistema foi criado em virtude de desabamentos, deslizamentos de terra e inundações causadas pelas fortes chuvas. 
Figura 5: Naomi Campbell veste a camiseta Rio Contra Dengue



Fonte: farodevigo.es

Reconhecido ícone de moda, a top model Naomi Campbell vestiu a camiseta Rio Contra a Dengue no ano de 2008, em que foram mais de 240 mil casos da doença em todo o estado ${ }^{8}$. A campanha de prevenção é permanente e conta ainda com cartilhas, panfletos, banners, grupos de dedetização que visam minimizar e até erradicar focos do

\footnotetext{
${ }^{8}$ Fonte: http://www.cives.ufrj.br/informacao/dengue/den-Rio2008.html
} 
mosquito Aedes aegypti. A dengue é considerada uma doença tropical e segundo a Organização Mundial da Saúde $^{9}$, afeta de maneira desproporcional as populações pobres e marginalizadas.

A camiseta Rio contra a Dengue também é um dos materiais criados pelo governo do Estado na prevenção da doença. Após Naomi vestir a peça, diversos veículos divulgaram a notícia, contribuindo para alertar ainda mais da necessidade do combate à dengue. Os governos do Estado e município do Rio de Janeiro produziram camisetas distribuindo gratuitamente para a população carente. Essas peças são consideradas parte de material de prevenção contra epidemias e desastres. Estariam os governos com essas camisetas, interferindo nas aparências de seus cidadãos? A socióloga Marie-Thérèse Duflos-Priot, ao estudar inúmeros casos da aparência como representação social, destacou que o indivíduo, embora padronizado, pode controlar sua aparência:

\footnotetext{
A informação emitida pelo indivíduo pode ser mais ou menos consciente e controlado por ele. Em alguns casos, o indivíduo pode procurar influenciar a informação emitida por sua aparência, alterando alguns dos seus elementos, então para um ato de comunicação (DUFLOS-PRIOT, 1981, p.64).
}

No caso Alerta Rio: A consciência da informação veio da Prefeitura e da Defesa Civil, que cumprem seus papéis de orientação a população. Essa consciencia pediu para que o agente utilizasse a roupa como material de divulgação dessa ação. Todos os lugares que o agente passar, não será a voz dele a ser ouvido e sim a da Defesa Civil e sua política de emergência em casos de chuva.

Para Duflos-Priot (1981, p.68) cada pessoa é ao mesmo tempo, transmissora e receptora. $\mathrm{Na}$ relação da comunicação intencional existe um controle no emissor da aparência que deve refletir as afiliações sociais do emitente.Embora a Prefeitura e a Defesa Civil sejam responsáveis pela mensagem, o agente comunitário que veste a roupa possui controle emissor da aparência. Poderia estar vestindo um casaco que escondesse as mensagens da estampa ou ter vestido a camiseta ao contrário, por exemplo.

Naomi vestiu para imprensa a camiseta com mangas cortadas. Mas, se a aparência da modelo influencia, no caso do Rio contra Dengue, vestida por ela, não

\footnotetext{
${ }^{9}$ Fonte: http://www.who.int/neglected_diseases/en/
} 
seria influente para ocupar um lugar na moda? Voltemos para Roland Barthes, pioneiro em analisar as funções da moda como signo, mais precisamente o significado do vestuário real. "O vestuário é, no sentido pleno, um "modelo social”, uma imagem mais ou menos padronizada de condutas coletivas previsíveis, e essencialmente nesse nível ele é significante" (Barthes, 2005, p. 279). Quando Naomi veste uma camiseta que revela papel social e seu prestígio de imagem projeta uma atenção maior sobre o assunto, sabemos: é uma roupa real, que todos podem ter acesso e, pelo fato de uma personalidade usar, torna-se publicamente aceitável que outras pessoas possam vestir a mesma peça.

"Percebe-se que a realidade implicada pelas funções de Moda é essencialmente definida por uma contingência; não é uma realidade transitiva; mais uma vez, é uma realidade vivenciada de modo fantasioso, é o real irreal do romance, enfático na proporção de sua irrealidade" (Barthes, 2009, p. 393). Falar de dengue ou de sirene em meio a deslizamento de terra não contrasta com tantos termos glamurosos da moda como marsala, pantone, cocktail dress. Há um distanciamento técnico entre estes dois mundos. Barthes fala em embaraço e tensão constitutiva das sociedades divididas entre a realidade e a linguagem $(2009$, p.257).

\footnotetext{
Por mais funcional que seja, o vestuário real sempre comporta um elemento signalético, uma vez que toda função é pelo menos signo de si mesma; o macacão de trabalho serve para trabalhar, mas também ostenta trabalho; a capa de chuva protege da chuva, mas também a significa (...), portanto, não há objeto normatizado (padronizado) que seja inteiramente esgotado por práxis puras: todo objeto é também um signo (BARTHES, 2009, p.390)
}

O signo da camiseta governamental, ainda que Naomi tenha usado, não corresponde à realidade do público idealizado pela moda porque o signo da dengue é de casa abandonada, acumulo de água e sujeira. E a camiseta da sirene é signo de deslizamento de terra para os que moram em zonas de risco. O sentido do vestuário como fato social é sua função de significar e os valores que o poder criador da sociedade tem de si mesma (Barthes, 2009, p. 275-281). Cabe aos governos explorar a massificação do vestuário que possui mensagens de suas práticas políticas. Para eles quanto maior o número de pessoas vestindo suas camisetas, mais efeito será a afirmação de suas mensagens. Os governos tendem a assumir a identidade visual das camisetas, na maior parte das vezes com visualidades nada interessantes, do ponto de vista do design, não associando a imagem da estampa a um criador (campo onde o cidadão 
torna-se cliente e possui muitas outras opções de cores, padronagens para uso) evidenciando sua lógica preventiva e assistencial.

Essas camisetas são distribuídas para centenas e até milhares de pessoas, isso pode ser considerado uma tendência de moda criada não por sua indústria, mas pela indústria política?

\title{
4. Sociologia das tendências
}

A palavra tendência é comumente associada a moda. Para Guillaume Erner em $A$ Sociologia das Tendências, a questão é mais ampla:

\begin{abstract}
A mesma palavra serve para nomear movimentos básicos da sociedade e fenômenos subterrâneos talvez condenados à invisibilidade. Mais ainda, a noção de tendência pode designar fenômenos fúteis - o hit do verão- e questões muito mais sérias - da "teologia da libertação" ao desenvolvimento sustentável. Por fim, além de, às vezes, o termo designar fenômenos comerciais, ele também se refere a objetos que ignoram qualquer lógica econômica, como a maneira de vestir uma roupa- do avesso ou não, para dentro da calça- ou a difusão rápida de uma expressão (ERNER, 2015, p.11).
\end{abstract}

Camisetas com mensagens de inclusão social ou inscrições governamentais é uma tendência caracterizada pela criação de um produto que será distribuído gratuitamente para as massas pois há o interesse de explicitar para a sociedade suas práticas de maneiras quase pedagógicas.

As mensagens dessas camisetas devem conter explicitamente suas justificativas na estampa (exemplo: "ao ouvir as sirenes", a estampa indica como o morador deve se comportar). A motivação da camiseta não é de produzir uma moda no sentido estrito da estética, mas uma condução comportamental e também uma forma de obediência civil.

O individualismo democrático foi o responsável por gerar as tendências. Como Tocqueville destacou, a democracia não é apenas uma forma de governo; ela também é um modo de organização da sociedade. Ela torna os indivíduos formalmente livres e iguais; emancipa-os dos poderes tradicionais, seja da monarquia ou da religião. Mas essa autonomia leva a uma situação paradoxal; os indivíduos se veem sob o jugo de um novo poder, tão constrangedor quanto o anterior: a opinião pública. As tendências encarnam as decisões do governo dessa opinião pública (...) essa autonomia parece em grande parte fictícia: como explicar que ela resulte numa obediência às tendências? Os homens se livraram do uniforme para cair na uniformidade? (ERNER, 2015, p. 85-87). 
A decisão dos governos em estampar camisetas, servem de uma maneira barata como forma de divulgação e dominância de suas atitudes. Ao invés de realizarem mudanças estruturais profundas como saneamento básico, coleta de lixo e outras responsabilidades que cabem ao poder público, estampam camisetas para a população carregar em seu corpo, as marcas de seu suposto legado político. No caso do Rio contra a dengue quem fala do governo é a Naomi Campbell. A imagem da modelo projetou mensagem mediada pela estampa (esfera pública) que alertava sobre os perigos da dengue no estado.

Em Alerta Rio o usuário da camiseta não fala. Quem fala é a Prefeitura e a Defesa Civil: "Um costureiro, segundo Bordieu, consegue traduzir em roupa, um determinado capital social e cultural. Ele transpõe para suas criações indumentárias os gostos da classe social à qual pertence, a preocupação da distinção social desta classe" (Erner, 2015, p.79). Por representação, podemos dizer que os estilistas no caso das camisetas foram o governo municipal e estadual, movidos pela necessidade de divulgar e proteger a população mais pobre de eventuais riscos da estação.

\section{Por que essas camisetas circulam entre os mais pobres?}

Os pequenos proprietários camponeses não podem representar a si mesmos; devem ser representados. Seu representante deve se mostrar simultaneamente como seu mestre, como uma autoridade sobre eles, e como o poder governamental irrestrito que os protege das outras classes e lhes envia a chuva e o sol dos céus (...) tal modelo de dissimulação social (...) implica não apenas uma crítica ao sujeito como um agente individual, mas também uma crítica à subjetividade de um agenciamento coletivo (SPIVAK, 2010, p. 36)

Pessoas necessitam de roupas, comidas e de trabalho para viver. Camisetas governamentais são materiais de divulgação de campanhas, tem distribuição fácil e gratuita, podendo ser usadas por todos. Inclusive por quem não tem o que vestir. Essas peças são negadas pelo núcleo da moda porque há a consciência de classe.

\footnotetext{
"A consciência da classe permanece atrelada a um sentimento de comunidade ligado por conexões nacionais e por organizações políticas, e não àquele outro sentimento de comunidade cujo modelo estrutural é a família. Embora não seja identificada com a natureza, a família aqui está agrupada em torno do que Marx chama de "troca natural" que é, filosoficamente falando, um "marcador de lugar" para o valor de uso" (SPIVAK, 2010, p.38)
} 
O marcador de lugar de quem consome camisetas com informações sobre educação social e cidadania fornecidas pelo governo não produz a elegância e o desejo de mudar o mundo através do consumo idealizado pelos desenvolvedores da moda. A roupa dos subalternos oferecida pela política pública, embora necessária, deve ser cada vez mais questionada.

\begin{abstract}
A pergunta é por que as classes subalternas colaboram com tanta frequência com quem as oprime? (...) Nos estudos antropológicos sobre as instituições governamentais que se ocupam das culturas populares, bem como nos dedicados às estratégias das corporações comunicacionais, tem-se demonstrado que o poder dessas instituições e corporações se conquista e renova através da disseminação dos centros, da multipolaridade das iniciativas e da adaptação das ações e mensagens à variedade de destinatários e de referências culturais que, em cada caso, ordenam suas identidades (Canclini, 2006, p.201).
\end{abstract}

De um lado, grandes corporações vendem camisetas que prometem ajudar a mudar o mundo (pagando os custos da produção). De outro, governos e políticos produzem mais camisetas e as distribuem gratuitamente afirmando estarem divulgando seus cuidados na sociedade (também pagando os custos da produção). Esse atos, embora distintos, podem estar de alguma maneira interligados?

Para o professor de governo e direito da Lafayette College, nos Estados Unidos, Joshua I. Miller no artigo intitulado Fashion and Democratic Relationships afirma que muitas pessoas observam a moda como trivial, mas que há mensagens de orientação aos cidadãos, importantes para o processo democrático:

\footnotetext{
A moda afeta a percepção dos cidadãos e influencia suas obrigações políticas (... ) Os cidadãos são unidos por certos valores, histórias e experiências comuns e, portanto, se sentem parte da mesma cidade ou país. Se os cidadãos se vêem como membros de mundos radicalmente diferentes, divididos por profundas divisões de riqueza e status, eles não podem imaginar a possibilidade de uma ação comum, mas se as suas roupas fazem lembrar das ligações de uns com os outros, eles podem se sentirem menos isolados e enfraquecidos (MILLER, 2005, p.5).
}

A camiseta Rio contra a dengue aproximou a imagem de Naomi Campbell (comumente associada a produtos de alto luxo) aos moradores de comunidades carentes que sofriam na epidemia de dengue, havendo um sentido de igualdade, representação e solidariedade. 
Joshua Miller (2005) discute um tema implícito em Veblen: os efeitos da moda em laços políticos, pontuando que conflitos entre cidadãos e filiações com base na raça, classe e gênero muitas vezes se expressam na roupa. Também afirma que as roupas facilitam o ideal de igualdade e diálogo, ressaltando as atitudes democráticas em direção ao que os outros estão vestindo.

\begin{abstract}
Descrevo dois tipos de relações políticas promovidas por roupas: a desigualdade e a solidariedade. Outro tipo de laço cívico é criado pelas mensagens políticas que emanam das roupas (...) As pessoas transmitem mensagens vagas ou explícitas ( ... ) estas declarações de moda podem livremente juntar os cidadãos numa espécie de conversa política (MILLER, 2005, p.18)
\end{abstract}

Após Naomi vestir a camiseta contra a dengue, diversos veículos de comunicação noticiaram o evento e a divulgação contribuiu mais uma vez para alertar a população da importância de se combater a epidemia. Entre a desigualdade e a solidariedade, o cidadão comum é afetado por informações e práticas de consumo e política. A camiseta intermedia estes deslocamentos.

Hoje há atividades como a costumização pelo DIY (Do it yourself) em que cada cidadão pode criar sua camiseta, mostrando apoio a movimentos ou descontentamentos com a política. Recentemente aconteceu no Rio de Janeiro um evento criado pelo facebook, chamado Camisetada pela Democracia, reunindo mais de 300 pessoas na praia do Leme, que levaram camisetas em branco para que outros artistas pudessem pintá-las com lata de tinta e stencil diversos. Se a política pode polarizar questões, a camiseta é ponto de apoio importante: ato democrático.

\footnotetext{
"Pode-ser dizer que, nos últimos anos, as relações entre a camiseta e a política se ampliaram e diversificaram ao ponto de uma generalização aparentemente promíscua, mas, na verdade, genuinamente democrática. Hoje, a camiseta serve a todas as causas e não, discriminadamente, às mais libertárias, como em outros tempos" (MACIEL,1988, p.69).
}

\title{
Conclusão
}

As camisetas com mensagens de inclusão social ou desejo de mudança no mundo, exprimem conversas políticas. Para muitas pessoas essas roupas não dizem nada: Seja porque tentam fugir dela, seja porque não se sintam representadas. 
Muito embora grandes designers já tenham realizado trabalhos com estampas de camisetas revertidas para a caridade (o caso de Ralph Lauren com o alvo e o pônei rosa), esse tipo de design é pago e tem intuito de reverter renda para causas independentes das ações governistas. Contraditoriamente, uma empresa gasta na confecção da camiseta e posteriormente na divulgação para influenciar o consumidor a adotar/comprar a causa, vinculando a um voto comercial-civil. Os governos também gastam na confecção da peça, mas não a vendem como um objeto que reverte lucro. $\mathrm{O}$ benefício da peça é divulgar sua aparente proteção social.

Seja camiseta grifada ou não, governamental ou não, a importância social dessas peças é inegável sobre vários aspectos, ainda que imersas em um jogo subverto de valores. A informação transmitida através das estampas consegue chegar a lugares incalculáveis. O governo assume o lugar do estilista ao validar um produto do vestuário de acordo com os seus padrões e regras.

Nas estampas governistas ficam evidentes marcadores de classe, consciências de lugar, emissões de aparência, embaraço e tensões constitutivas das sociedades. Essas camisetas são vestidas na sua maioria por humildes e sem tetos -o que distancia a imagem da elegância através da riqueza desejada pelo mundo da moda. Há mais propensão a um ato civil do que moda (como um elemento primeiro e efêmero) sendo efetuada nestas camisetas.

Ao vestir uma camiseta com mensagens sociais, o cidadão age dentro do princípio da solidariedade em distribuir ao máximo número de pessoas da sua comunidade tal informação enviada através de sua roupa. A camiseta padronizada com estas informações contribui para diminuir a desigualdade aparente (é o caso de Naomi vestindo a mesma camiseta dos mais humildes).

Quanto mais as roupas usadas pelas pessoas expressarem sua verdadeira identidade social e houverem representações nos meios de comunicação desta realidade, menos desigual será o sentido da moda, ainda que isto signifique lidar muito mais com o vestuário real do que o vestuário irreal, aqueles em que a massa jamais pode alcançar. No máximo, contentar-se com sua réplica. 
Embora a coleção de Rei Kawakubo ${ }^{10}$ quando surgiu na década de 80 foi apontada por ser inspirar no estilo de mendigos e John Galliano ${ }^{11}$, nos jornais que os sem tetos usavam para se cobrir nas margens do Rio Sena, estes exemplos produziram uma extratificação do humanitário que não é de interesse político, mas um empréstimo estético, simulacro das verdades figurativas dos marginais para atualizar o guarda roupa da burguesia.

A criação da moda deve funcionar como um sonho em que muitas vezes paralisa a realidade. Negar a transformação da realidade é paradoxo muito complexo para a moda. Ama-se comprar roupas lindas e baratas. Ignora-se o trabalho escravo. Ama-se top models fazendo trabalhos comunitários. Ignora-se no dia-dia a realidade das comunidades.

Artigo recebido em Agosto de 2015. Aprovado em Maio de 2016

DOI:http://dx.doi.org/105965/1982615x09182016171

\section{Referências bibliográficas:}

BARTHES, R. Inéditos Vol. 3: Imagem e Moda. São Paulo: Editora Martins Fontes, 2005 .

BARTHES, R. Mitologias. Rio de Janeiro: Editora Difel, 2013.

BARTHES, R. O Sistema da Moda. São Paulo: Editora WMF Martins Fontes, 2009.

CANCLINI, N.C. Consumidores e cidadãos. Rio de Janeiro: Editora UFRJ, 2006.

ERNER, G. Sociologia das tendências. São Paulo: Editora Gustavo Gilli, 2015.

SPIVAK, G. C. Pode o subalterno falar? Belo Horizonte: Editora UFMG, 2010.

VÁRIOS AUTORES. A História da Camiseta. São Paulo: Editora Cia. Hering, 1988.

\section{Artigos:}

\footnotetext{
${ }^{10} \mathrm{https}$ ://vaillantmartien.wordpress.com/2013/05/12/rage-against-the-machine-most-rebellious-momentsin-fashion/

${ }^{11}$ http://www.nytimes.com/2000/01/23/opinion/liberties-haute-homeless.html
} 
DUFLOS-PRIOT, M.T. L'apparence individuelle et la représentation de la réalité humaine et des classes sociales, Cahiers Internationaux de Sociologie, França, Vol. 70 p. 63-84, 1981.

MILlER, J. I. Fashion and Democratic Relationships. Polity. EUA. Vol. 37, p.3-23, 2005.

\section{Legislação:}

BRASIL. Constituição (1988). Constituição da República Federativa do Brasil: promulgada em 5 de outubro de 1988. Brasília, DF: Senado, 1988. Disponível em: http://bd.camara.gov.br/bd/bitstream/handle/bdcamara/15261/constituicao_federal_35ed .pdf

Acesso em 30/08/2015

FRANÇA. ONU. Declaração Universal dos Direitos Humanos, 1948. Disponível em: http:// unesdoc.unesco.org /images/0013/ 001394/ 139423por.pdf Acesso em 30/08/15

\section{Sites:}

Alerta rio:

http://alertario.rio.rj.gov.br. Acesso em: 20/08/15.

O Câncer de Mama no Alvo da Moda:

http://www.ocancerdemamanoalvodamoda.com.br/nossaHistoria.asp. Acesso em: 20/08/15.

Organização Mundial da Saúde:

http://www.who.int/neglected_diseases/en/. Acesso em: 20/08/15.

Rio contra a Dengue:

http://www.riocontradengue.com.br. Acesso em: 20/08/15. 